\title{
ATUAÇÃO DO SETOR PRIVADO NO PROCESSO DE CONSTRUÇÃO CURRICULAR: O SEQUESTRO DOS FINS PÚBLICOS DA EDUCAÇÃO ${ }^{1}$
}

\author{
IMPACTO DEL SECTOR PRIVADO EN EL PROCESO DE CONSTRUCCIÓN \\ CURRICULAR: EL SECUESTRO DE FINES PÚBLICOS DE LA EDUCACIÓN
}

INCIDENCE OF THE PRIVATE SECTOR IN THE CURRICULUM BUILDING PROCESS: THE APPROPRIATION OF THE PUBLIC PURPOSES OF EDUCATION

Raquel Fontes BORGHI²

RESUMO: No Brasil, assim como em muitos outros países, a presença do setor privado na educação vem aumentando de modo exponencial conforme apontam muitos estudos. Tal movimento de avanço do setor privado na educação pode ser compreendido no movimento de crise e expansão capitalista. Este artigo se constitui em um ensaio teórico baseado nas pesquisas realizadas pela autora em mais de 15 anos de estudos acerca da temática da privatização da educação. Tem por objetivo refletir acerca da incidência do setor privado no "processo de construção curricular" e destacar que este movimento tem levado ao sequestro dos fins públicos da educação pelos reformadores empresariais. Aponta-se para as potencialidades da gestão democrática como possibilidade contra hegemônica na perspectiva de definição de fins públicos e coletivos para a educação.

PALAVRAS-CHAVE: Currículo. Mercadorização. Privatização. Gestão democrática.

RESUMEN: En Brasil, como en muchos otros países, la presencia del sector privado en la educación ha aumentado exponencialmente, como señalan muchos estudios. Este movimiento de avance del sector privado en la educación puede entenderse en el movimiento de crisis y expansión capitalista. Este artículo es un ensayo teórico basado en la investigación realizada por el autor durante más de 15 años de estudios sobre el tema de la privatización de la educación. Pretende reflexionar sobre la incidencia del sector privado en el "proceso de construcción del currículo" y destacar que este movimiento ha llevado al secuestro de los fines públicos de la educación por parte de los reformistas empresariales. Señala el potencial de la gestión democrática como posibilidad contrahegemónica en la perspectiva de definir los fines públicos y colectivos de la educación.

PALABRAS CLAVE: Currículum. Comercialización. Privatización. Gestión democrática.

\footnotetext{
${ }^{1}$ Esta pesquisa foi apresentada no VI Congresso Ibero-Americano de Política e Administração da Educação e IX Congresso Luso-Brasileiro de Política e Administração da Educação (2018).

${ }^{2}$ Universidade Estadual Paulista (UNESP), Rio Claro - SP - Brasil. Docente do Departamento de Educação e Coordenadora do Programa de Pós-graduação em Educação. Doutorado em Educação Escolar (UNESP). ORCID: https://orcid.org/0000-0003-1486-7396. E-mail: raquel.borghi@unesp.br
}

RPGE- Revista on line de Política e Gestão Educacional, Araraquara, v. 25, n. 3, p. 2744-2758, set./dez. 2021. e-ISSN: 1519-9029 DOI: https://doi.org/10.22633/rpge.v25i3.14903 
ABSTRACT: In Brazil, as in many other countries, the presence of the private sector in education has been increasing exponentially, as pointed out by many studies. Such a movement for the advancement of the private sector in education can be understood in the movement of crisis and capitalist expansion. This article is a theoretical essay based on research carried out by the author in more than 15 years of studies on the theme of privatization of education. It aims to reflect on the incidence of the private sector in the "curriculum construction process" and to highlight that this movement has led to the appropriation of the public purposes of education by business reformers. It points to the potential of democratic management as a possibility against hegemony in the perspective of defining public and collective purposes for education.

KEYWORDS: Curriculum. Commodification. Privatization. Democratic management.

\section{Introdução}

Este artigo é uma reflexão teórica decorrente de pesquisas que vêm sendo realizadas pela autora com a temática da privatização da educação no âmbito de um grupo interinstitucional denominado GREPPE - Grupo de Estudos e Pesquisas em Política Educacional. O objetivo é apresentar uma reflexão acerca da incidência do setor privado no "processo de construção curricular"3 e destacar que este movimento tem levado ao sequestro dos fins públicos da educação pelos "reformadores empresariais".

Temos presenciado na última década uma intensificação de processos de privatização da educação no Brasil (ADRIÃO et al., 2009; BORGHI, 2018b; GARCIA; 2006, SANTOS, 2012; PERONI, 2018). Muitos destes estudos evidenciam que os processos de privatização na educação não correspondem exclusivamente ao modelo tradicional de transferência da propriedade estatal para a privada.

Sader (2003), por exemplo, afirma que a mercantilização da educação não requer necessariamente a privatização do seu fornecimento. Para o autor, embora formalmente estatal, uma instituição pode ter objetivos privados (atender ao mercado) e um funcionamento orientado por pressupostos liberais como o individualismo, a competição entre os indivíduos e, genericamente, uma concepção de mundo operacional ao capital.

Entendemos aqui a privatização em uma concepção ampla que vem se dando em um contexto de reconfiguração das fronteiras entre o público e o privado. Neste sentido, os arranjos e estratégias entre o público e o privado são diversos e têm constituído e consolidado

\footnotetext{
3 O termo "processo de construção curricular" se baseia nos escritos de Gimeno Sacristan (2000) e será apresentado mais a frente.

${ }^{4}$ Reformadores empresariais é um termo usado por Daiane Ravitch (2011) e Freitas (2018).
} 
um intenso processo de privatização. Belfield e Levin (2004, p.19) afirmam que a privatização:

É um termo guarda-chuva referente a diferentes programas e políticas educacionais. Como uma definição geral, as privatizações transferem as atividades, os ativos e as responsabilidades do governo/instituições e organizações públicas para os indivíduos e as agências. Além disso, a privatização é frequentemente pensada como "liberalização" - onde agentes dos países são isentos de regulamentações governamentais, ou como "mercantilização" -, onde novos mercados são criados como serviços alternativos aos governamentais (BELFIELD; LEVIN, 2004, p. 19).

Muitas são as pesquisas que evidenciam este processo, mapeando e analisando os diferentes espaços e as múltiplas estratégias de privatização. Pesquisas do GREPPE - Grupo de Estudos e Pesquisas em Política Educacional, vêm mapeando diferentes estratégias de privatização na educação, particularmente nas denominadas dimensões da gestão, oferta e currículo. O Grupo disponibiliza um mapeamento da inserção do setor privado na educação básica nas diferentes redes estaduais do Brasil, evidenciando como as redes públicas caminham em direção à privatização.

Em seu conjunto, os projetos de pesquisa do GREPPE analisaram, em diferentes contextos, distintas formas pelas quais a educação básica vem sendo privatizada. Ao longo das pesquisas três dimensões da privatização da educação básica foram se destacando e tornaram-se dimensões de análise. Tal divisão decorre de estratégia metodológica reconhecendo-se que a política educacional envolve a interconexão entre tais dimensões, conforme Adrião (2018a).

A primeira dimensão, relativa à privatização da oferta educacional, operacionaliza-se por meio de três formas: financiamento público (direta ou indiretamente) à oferta educacional por provedor privado, aumento das matrículas em estabelecimentos particulares e a introdução de políticas ou programas de escolha parental (voucher, educação domiciliar e charter school). A segunda dimensão refere-se à privatização da gestão da educação, captada em dois âmbitos: privatização da gestão educacional, envolvendo a proposição por atores privados de sistemáticas que assumem caráter sistêmicos, como a introdução de ranqueamentos, bonificações ou formas de terceirização do trabalho docente; e privatização da gestão escolar, relativa à introdução de mecanismos de privatização no âmbito de unidades escolares específicas. A última refere-se à privatização do currículo, trata-se da privatização dos processos pedagógicos strictu sensu, envolvendo a incidência do setor privado sobre as 
relações entre professor/a, estudante e conhecimento e insumos curriculares (ADRIÃO, 2018a).

Neste artigo, o foco está na dimensão da privatização do currículo. Considerando o atual desmonte das fronteiras entre o público e o privado, é urgente a disputa pelo sentido público da educação já apontada por Borghi (2018b). A questão que se coloca é a seguinte: é pública uma educação em que os currículos/fins são definidos por reformadores empresariais? Tal questão é de grande relevância se considerarmos que o sentido da educação pública está sendo disputado, cooptado, alargado em sua abrangência. É preciso defender a educação pública, de financiamento público e de gestão pública - a única que pode ser democrática em sua essência e estabelecer sentidos e fins coletivos para a educação.

Primeiramente será apresentada a concepção de currículo enquanto processo em construção com base nos estudos de Gimeno Sacristan (2000). Em seguida, são apresentados exemplos de como se dá a materialidade da incidência do setor privado no processo de construção curricular. Por fim, são elencadas considerações acerca desta atuação dos reformadores empresariais e o sequestro dos fins públicos da educação e aponta-se para uma necessária ação contra hegemônica no sentido de retomar e restabelecer fins públicos e coletivos para a educação.

Partimos do entendimento de que o avanço do setor privado na educação e o desmonte das fronteiras entre o público e o privado deve ser compreendido no movimento de crise e expansão capitalista, como defendem Silva Jr e Sguissardi (2001, p. 101),

o entendimento do público e do privado no capitalismo e de seu movimento somente se pode dar com a compreensão do movimento do capital e das crises do capitalismo, que instalam novos modos de conformação do público e do privado, que redesenham as relações entre o estado e a sociedade e reconfiguram as instituições da sociedade civil e do estado.

Em artigo de 2018, Peroni questiona como a redefinição no papel do Estado está reorganizando as fronteiras entre o público e o privado. Para a autora, o estado continua sendo o responsável pelo acesso, mas o conteúdo pedagógico e a gestão da escola são cada vez mais determinados por instituições que introduzem a lógica mercantil. É o privado mercantil definindo a educação pública.

Também se considera aqui, com Borghi (2018b), que os processos de privatização vêm se dando em um contexto de expropriação do direito à educação e colocando em xeque a perspectiva e o ideal de universalização da educação. Em última instância, afirma a autora, tem-se a privatização de um direito. Para a autora, a concepção de educação pública está hoje 
em disputa e é de grande importância definir qual a essência da educação pública que defendemos e que nos permite fazer frente a defesa, hoje quase hegemônica, da privatização da educação.

\section{A atuação do setor privado no processo de construção curricular}

O percurso aqui trilhado inicia-se pela concepção de currículo, concordando com Apple (2002, p. 59-60), quando afirma que este é:

produto de tensões, conflitos e concessões culturais, políticas e econômicas que organizam e desorganizam um povo (...) sempre existe, pois, uma política do conhecimento oficial, uma política que exprime o conflito em torno daquilo que alguns veem simplesmente como descrições neutras do mundo e outros, como concepções de elite que privilegiam determinados grupos e marginalizam outros.

Para o autor, o currículo não é somente um documento impresso das instituições de ensino, mas um documento que reflete todo um complexo de relações sociais de um determinado momento histórico. Apple (2003, p. 79-80) afirma que:

Um 'novo' conjunto de acordos, uma nova aliança e um novo bloco de poder se formaram e estão tendo uma influência cada vez maior na educação e em todos os aspectos da vida social. Esse bloco de poder combina frações múltiplas de capital comprometidas com as soluções mercantilizadas que os neoliberais apresentam para os problemas educacionais, com os intelectuais neoconservadores que querem um 'retorno' a um padrão de qualidade melhor e a uma 'cultura comum', com os fundamentalistas religiosos populistas e autoritários, profundamente preocupados com a secularidade e a preservação de suas próprias tradições, e com frações particulares de profissionais qualificados da nova classe média, comprometidos com a ideologia e as técnicas de avaliação, mensuração e 'administração'. Embora existam tensões e conflitos evidentes no seio dessa aliança, em geral seus objetivos globais são oferecer as condições educacionais que seus componentes acreditam necessárias tanto para aumentar a competitividade internacional, o lucro e a disciplina quanto para nos fazer voltar a um passado romantizado de lar, família e escola 'ideais'.

Partimos, ainda, da concepção de currículo elaborada por Gimeno Sacristan (2000), para quem o currículo deve ser compreendido como um processo em construção, que vai se constituindo e se configurando em diferentes momentos, síntese de múltiplas determinações.

Enquanto um processo em construção, conforme Gimeno Sacristan (2000, p. 36),

currículo refere-se a um projeto seletivo de cultura que possui condicionantes extra-escolares, de ordem social, política e cultural, e que se constrói e se configura a partir das condições da escola, sendo determinado 
deste modo por condicionantes intra-escolares. O currículo não é estático, ele está sempre em processo de construção e desenvolvimento, abrangendo desde os níveis centrais da política curricular, até a sua concretização em sala de aula.

Nesta perspectiva, o currículo deve ser entendido como processo em construção, permeado por lutas, embates e tensões. Neste processo de construção curricular diferentes fatores internos e externos a escola, vão moldando, dando forma ao currículo.

Também para Ponce (2018), os currículos escolares são territórios de disputa política, onde está em jogo a educação que se deseja oferecer. Segundo a autora, esta é uma arena de disputas entre forças desproporcionais. É com esta interpretação que Borghi (2018b) afirma que no atual processo de expropriação do direito a educação e sua transformação em mercadoria, o mercado pode ser entendido como o atual "Big Brother", fazendo uma referência ao livro 1984 de George Orwell. Para a autora, os reformadores empresariais têm tido forte incidência no processo de construção curricular.

Também Ball (2014, p. 25) nos fala acerca da "universalização das relações sociais baseadas no mercado, com a correspondente penetração em quase todos os aspectos de nossas vidas, do discurso e/ou da prática de mercantilização, de acumulação de capital e de geração de lucros".

Entendemos aqui, que todo o processo de construção curricular vem sendo disputado. Gimeno aborda o processo de construção curricular a partir de diferentes momentos. $\mathrm{O}$ currículo prescrito corresponde às normas e diretrizes gerais que atuam como referência para a ordenação do sistema curricular - selecionam e distribuem o conhecimento dentro do sistema escolar. Já o currículo apresentado refere-se aos materiais elaborados para traduzir e clarificar aos professores o significado e conteúdo do currículo prescrito, realizando uma interpretação deste. O currículo planejado pelos professores são os planejamentos anuais, mensais, diários elaborados pelos professores, tendo como base as normas e diretrizes gerais e as necessidades particulares de seu alunado. O currículo em ação representa o momento da ação pedagógica, da prática docente em sala de aula; o currículo realizado compreende os efeitos produzidos pela prática, efeitos estes que são de diversas ordens e que afetam tanto os alunos como os professores. Por fim, o currículo avaliado, implica o momento da avaliação, que pode ser do rendimento dos alunos ou do programa curricular em si e sua concretização. 


\section{O processo de construção curricular e a atuação dos reformadores empresariais}

Como então o setor privado vem atuando ao longo deste complexo processo de desenvolvimento curricular?

No que se refere ao "currículo prescrito", definido por Gimeno Sacristan (2000) como as prescrições legais curriculares, Borghi (2018a) aponta a atuação do "Movimento Todos pela Base Nacional Comum" no processo de construção da Base Nacional Comum Curricular como um exemplo da forte incidência do setor privado. O Movimento pela Base Nacional Comum foi constituído em abril de 2013, segundo consta em seu site, tendo por objetivo discutir a criação de uma base comum que influenciasse na aprendizagem de cada estudante, na formação docente, nos recursos didáticos utilizados em sala, bem como nas avaliações externas. Atualmente, após a aprovação da nova BNCC, já há no site do Movimento um pacote de ações voltadas para a sua implementação e pronto para ser consumido por milhares de redes públicas municipais e estaduais de educação. São os chamados "reformadores empresariais" (FREITAS, 2012) pensando, ou melhor, ditando os currículos escolares. A questão é que, como aponta Oliveira (2003, p. 51) "por possuir uma compreensão economicista e fragmentária acerca das múltiplas relações nas quais os indivíduos estão inseridos, [o empresariado] termina por valorizar muito mais o papel da escola como espaço de preparo do indivíduo para o mercado de trabalho" reduzindo a educação aos interesses mercadológicos.

Freitas (2012), fazendo uma crítica a atuação dos reformadores empresariais na reforma curricular aponta que não se trata apenas de uma reforma curricular, mas, em última instância, da própria recomposição dos fins educacionais.

No que se refere ao "currículo apresentado" aos professores por meio da produção de materiais elaborados para traduzir e clarificar o significado e conteúdo do currículo prescrito, um exemplo da atuação do setor privado é a adoção, por muitas redes públicas, dos chamados "sistemas privados de ensino" (BORGHI, 2018a). Adrião et al. (2009), abordam esta tendência em artigo que trata do crescimento das parcerias, pela via dos contratos entre os municípios paulistas e empresas privadas da área educacional para a aquisição de "sistemas privados de ensino". As autoras entendem que essa compra representa mais do que a simples aquisição de materiais didáticos, dado se tratar de estratégia por meio da qual o setor privado amplia seu mercado, ao incidir sobre o espaço público. Na mesma medida, o setor público transfere parcela de suas responsabilidades para com a educação à iniciativa privada. Em 
estudo mais recente Adrião et al. (2016, p. 128, grifo do autor) alertam para as consequências deste processo de mercantilização para o direito à educação. Os autores afirmam que,

Grupos empresariais e conglomerados econômicos têm buscado outras formas de lucrar com a educação que não exclusivamente com a oferta direta do ensino (matrículas em escolas privadas), colocando em risco os paradigmas de direitos humanos educacionais, que são substituídos pela lógica de mercado baseada no custo $\times$ benefício e na visão dos estudantes como mercadorias - commodities.

Costola e Borghi (2018) apontam um outro exemplo da incidência dos reformadores empresariais. Para as autoras, o movimento empresarial, no Brasil, tem influenciado de forma significativa na agenda e na construção de políticas públicas. Elas afirmam que diversos campos de atuação se abrem no processo de implementação da BNCC. Neste sentido, há um vasto campo para a oferta privada de "soluções" e inovações"” para os "problemas" educacionais. Um dos setores de atuação do Movimento pela Base após a sua aprovação é justamente a elaboração de materiais didáticos e de apoio. Para Ball (2014, p. 59), há um vasto movimento formado por institutos, fundações, centros de pesquisa que têm como ponto de convergência "fazer do mercado a solução óbvia para os problemas sociais e econômicos". Para o autor, o trabalho dessas redes políticas e empresariais em prol do capitalismo neoliberal é um projeto supranacional capaz de promover mudanças políticas geradoras de mais lucro e novas oportunidades de negócios.

No "currículo planejado" podemos considerar os planejamentos anuais, mensais, diários elaborados pelos professores, tendo como base as normas e diretrizes gerais e as necessidades particulares de seu alunado. Nesta fase, o setor privado tem incidido fortemente, mas destacamos novamente a adoção de sistemas de ensino privados (SPEs) por redes de escolas públicas. Como já apresentado por ADRIÃO et al. (2009, p. 806),

Os SPEs consistem em uma cesta de produtos e serviços: integrada por atividades tradicionalmente desenvolvidas pelas equipes pedagógicas dos órgãos da administração pública e das escolas: formação continuada de educadores, acompanhamento e supervisão das atividades docentes; investimento na produção e distribuição de materiais didáticos aos alunos; processos de avaliação externa e interna, entre as principais encontradas.

Para Santos (2012), os processos pedagógicos padronizados impedem que a escola desenvolva seu projeto-político-pedagógico com autonomia e compromisso político transformador. Para ela, algumas questões fundamentam a elaboração de um PPP dentre as quais destacamos: Que sociedade queremos construir? Que escola é necessária para esta construção? Para a autora, em tempos de reestruturação neoliberal e desqualificação da ação 
política transformadora e militante, o direito de formular - e sobretudo de responder a estas questões foi confiscado pelo empresariado.

Neste sentido, assim como já apontado por Borghi (2018a), tais sistemas privados de ensino também têm interferência no que Gimeno Sacristãn (2000) denomina de "currículo em ação", que representa o momento da ação pedagógica, da prática docente em sala de aula. Treinamentos, capacitações, distribuição de materiais, controle da atuação docente em sala de aula, fazem parte dos pacotes de serviços privados. Em pesquisa do GREPPE coordenado por Garcia et al. (2014) os estudos evidenciaram as implicações da adoção de sistemas privados de ensino para a organização do trabalho, planejamento e trabalho docente nas redes públicas. No contexto desta mesma pesquisa, Bertagna e Borghi (2011) afirmaram que a reorganização do trabalho pedagógico das escolas públicas, que vinha sendo levada a efeito por empresas privadas, em prol de melhorias nos resultados nas avaliações externas, alterava o curso da trajetória que vinha se dando rumo à ampliação da autonomia e gestão escolar nas escolas públicas. Isto porque, a partir da "cesta de serviços" oferecidos pelas empresas privadas, observava-se que, além da organização e sistematização de conteúdos propostos nos sistemas apostilados e padronizados, as empresas ficavam responsáveis por pensar e planejar o trabalho pedagógico das escolas públicas. As autoras afirmam que relegar a organização do trabalho pedagógico às empresas privadas, é transferir a elas a discussão sobre os fins desejados para a educação pública.

Para Souza e Sarti (2013), a configuração de políticas de formação em serviço baseadas em cursos e calcadas em concepções que desqualificam o docente parecem atender bem a interesses de cunho mercantil, que visam à construção de um mercado da formação.

No âmbito do "currículo realizado" Gimeno Sacristan (2000) compreende os efeitos produzidos pela prática, efeitos estes que são de diversas ordens e que afetam tanto os alunos como os professores. Aqui, a própria mercadorização da educação, ou seja, sua transformação em mercadoria e investimento individual, traz implicações para a responsabilização de cada indivíduo pelo conhecimento. A inserção nos currículos atuais de conteúdos como projetos de vida, empreendedorismo, entre outros, exemplificam esta questão e levam o individualismo e a meritocracia ao seu limite.

Quanto ao "currículo avaliado", é possível afirmar que há um verdadeiro mercado de sistemas de avaliação em larga escala. São eles também, em grande parte, os responsáveis no Brasil pela defesa de currículos padronizados, como apontam Bertagna e Borghi (2011, p. 140): 
Outro aspecto que evidencia o novo rumo dado à organização do trabalho pedagógico da escola e que diverge das legislações referentes à gestão democrática e autonomia escolar é a defesa atual da padronização daquilo que se ensina nas escolas como estratégia para melhoria dos resultados nas avaliações externas.

Do modo como os sistemas de avaliação externos vem se efetivando em nosso país, é possível afirmar que estes são incompatíveis tanto com o direito à diferença - na medida em que induzem a padronização não há espaço para trabalhos diferenciados, atendimento aos diferentes ritmos de aprendizagem, aos alunos com necessidades especiais, etc; quanto com o direito à igualdade - como dizer que todos tem direito à uma educação de qualidade se a estratégia para a melhoria da qualidade é a competitividade que, em si, pressupõe um sistema educacional com oferta desigual?

\section{O sequestro dos fins públicos da educação}

A grande questão da privatização na área educacional é o fato de que os fins educacionais e, em última instancia, a proposta de formação humana, vem sendo definida, a partir dos princípios e valores do privado e da autovalorização do capital. Para Freitas, tal processo revela o sequestro da educação pública pelo empresariado. $\mathrm{O}$ autor afirma que "a educação está sendo sequestrada pelo empresariado para atender a seus objetivos de disputa ideológica" (FREITAS, 2018, p. 29). Segundo este autor, o neoliberalismo olha para a educação a partir de sua concepção de sociedade baseada em um livre mercado:

tendo assumido tal darwinismo social no âmbito da sociedade, justificando-o pela sobrevivência do indivíduo mais forte na concorrência do livre mercado, quer agora levá-lo para as escolas e disputar a hegemonia na formação da juventude dentro de sua lógica. Para esta vertente, se o mundo é pautado pela concorrência, há que se preparar as crianças para competir nele, tal como ele é. Nenhuma perspectiva de humanização ou transformação social é agregada aos processos educativos, daí seu caráter reacionário e conservador (FREITAS 2018, p. 28).

Freitas (2018) defende que essa é uma razão que deveria ser suficiente para nos afastarmos destas concepções de sociedade e de educação, mesmo que os resultados acadêmicos de desempenho venham a ser eficazes.

Também Santos (2012) aborda na mesma perspectiva o "sequestro" da educação pública. Para a autora

O esfacelamento da escola pública nas duas últimas décadas do século XX precede a seu sequestro salvacionaista pelo mercado. O bloco hegemônico 
investe na desqualificação da escola pública - contando, inclusive, com a adesão despercebida de setores populares - para, em seguida, apresentar a solução: entregar a escola à competência administrativa dos senhores de negócios e a seus institutos (SANTOS, 2012, p. 11).

Neste sentido também, a mesma autora denuncia que:

Todo o processo de produção pedagógica é submetido à lógica do mercado: relações ensino aprendizagem, conteúdos programáticos, princípios pedagógicos do currículo e avaliação dos resultados. $\mathrm{O}$ sentido e as finalidades da educação incorporam a mercadorização já no âmbito da produção (SANTOS, 2012, p. 20).

Deste modo, é possível afirmar que a incidência do setor privado nas políticas atuais de currículo revela de modo mais abrangente o próprio sequestro dos fins e valores públicos da educação. Estamos efetivamente vivenciando um processo de privatização dos currículos e, neste sentido, de sequestro dos fins educacionais pelo empresariado em uma disputa pelo monopólio da formação humana. Neste sentido, a mercadorização da educação refere-se à recomposição da própria natureza da educação e seus fins, transformando-a em mercadoria. Como afirma Borghi (2018a, p. 105) "a restrição dos fins da educação a uma perspectiva individual e a seu impacto econômico é uma das mais abrangentes estratégias privatizantes".

Para Paro (2000, p. 3, grifos do autor), a escola tem como fim produzir um ser humano histórico e sujeito:

Entendida a educação como atualização histórica do homem e condição imprescindível, embora não suficiente, para que ele, pela apropriação do saber produzido historicamente, construa sua própria humanidade históricosocial, parece justo admitir que a escola fundamental deva pautar-se pela realização de objetivos numa dupla dimensão: individual e social. A dimensão individual diz respeito ao provimento do saber necessário ao autodesenvolvimento do educando, dando-lhe condições de realizar seu bem-estar pessoal e o usufruto dos bens sociais e culturais postos ao alcance dos cidadãos; em síntese, trata-se de educar para o "viver bem" (Ortega y Gasset, 1963). Por sua vez, a dimensão social liga-se à formação do cidadão tendo em vista sua contribuição para a sociedade, de modo que sua atuação concorra para a construção de uma ordem social mais adequada à realização do "viver bem" de todos, ou seja, para a realização da liberdade enquanto construção social. Se entendermos a democracia nesse sentido mais elevado de mediação para a construção e exercício da liberdade social, englobando todos os meios e esforços que se utilizam para concretizar o entendimento entre grupos e pessoas, a partir de valores construídos historicamente (cf. Paro, 1999, pp. 105-106), podemos dizer que essa dimensão social dos objetivos da escola se sintetiza na educação para a democracia. 
Enquanto investimento individual e mercadoria, a educação perde sua dimensão social e coletiva, portanto, pública. Perde-se, em última instancia, a proposta de uma "educação para a democracia" proposta por Paro (2000).

Quais os limites e possibilidades de uma ação contra hegemônica?

Garcia (2006, p. 88) aponta a "necessidade de políticas públicas que de fato se comprometam com a gestão democrática da educação e da escola, produzindo condições favorecedoras à exploração da potencialidade transformadora da instituição escolar".

É urgente a revitalização desta luta pela gestão democrática para a garantia do direito à uma educação verdadeiramente pública. A gestão democrática é imprescindível para a definição de fins públicos e coletivos, ou seja, para uma educação essencialmente pública. É ela princípio fundamente da educação pública, repleta de potencialidades para uma ação contra hegemônica em direção ao resgate dos sentidos coletivos de uma educação essencialmente pública.

Há uma estratégia atual deliberada de simbiose entre o público e o privado, favorecendo um alargamento da abrangência da concepção de educação pública, integrando a ela diversos arranjos entre o público e o privado. Por isso, destaca-se aqui a importância de disputar a concepção e essência da educação pública que defendemos, bem como defender a gestão democrática como a única forma de gestão capaz de definir fins e sentidos coletivos para a educação.

Também entra em cena na disputa sobre o currículo e os fins da educação o movimento atual "Escola sem partido". Como se articulam e se distanciam os reformadores empresariais e setores religiosos do movimento escola sem partido na disputa pela pelos fins da educação? Este é tema para outras reflexões!

\section{REFERÊNCIAS}

ADRIÃO, T. Introdução. In: GARCIA, T; ADRIÃO, T. (Org.). Currículo, gestão e oferta da educação básica brasileira: incidências de atores privados nos sistemas estaduais (20052015). Curitiba, PR: CRV, 2018a.

\section{ADRIÃO, T. (Coord.). Mapeamento das estratégias de privatização da educação básica}

no Brasil (2005-15). 2018b. Disponível em: https://www.greppe.

fe.unicamp.br/pt.br/mapeamento_da_insercao_do_setor_privado_nas_redes_estaduais_de_ed ucacao_2005_2015. Acesso em: 10 ago. 2020.

ADRIÃO, T. et al. Grupos empresariais na educação básica pública brasileira: limites à efetivação do direito à educação. Educação e Sociedade, Campinas (SP), v. 37, p. 113-131, 
2016. Disponível em: https://www.scielo.br/pdf/es/v37n134/1678-4626-es-37-134-00113.pdf. Acesso em: 10 jul. 2020.

ADRIÃO, T. et al. Uma modalidade peculiar de privatização da educação pública: a aquisição de "sistemas de ensino" por municípios paulistas. Educação e Sociedade, Campinas (SP), v. 30, n. 108, p. 183-198, 2009. Disponível em:

https://www.scielo.br/scielo.php?script=sci_arttext\&pid=S0101-73302009000300009. Acesso em: 15 set. 2020.

APPLE, M. Educando a direita. Mercados, padrões, deus e desigualdade. São Paulo, SP: Cortez/Instituto Paulo Freire, 2003.

APPLE, M. Repensando ideologia e currículo. In: MOREIRA, A. SILVA, T. (Org.)

Currículo, cultura e sociedade. 7. ed. São Paulo, SP: Cortez, 2002.

BALL, S. Educação Global S. A.: novas redes de políticas e o imaginário neoliberal. Trad. Janete Bridon. Ponta Grossa, PR: UEPG. 2014. 270 p.

BELFIELD, C. R.; LEVIN, H. M. A privatização da educação: causas e implicações. Lisboa, Portugal: Edições ASA, 2004.

BERTAGNA, R.; BORGHI, R. Possíveis relações entre avaliação e sistemas apostilados privados em escolas públicas. Revista Educação: teoria e prática, Rio Claro (SP), v. 21, n. 38, p. 132-146, 2011. Disponível em:

https://www.periodicos.rc.biblioteca.unesp.br/index.php/educacao/article/view/5269. Acesso em: 10 dez. 2020.

BORGHI, R. Que educação é pública? A atuação do setor privado no processo de construção curricular. In: CONGRESSO IBERO-AMERICANO DE POLÍTICA E ADMINISTRAÇÃO DA EDUCAÇÃO, 6.; CONGRESSO LUSO-BRASILEIRO DE POLÍTICA E ADMINISTRAÇÃO DA EDUCAÇÃO, 9., 2018, Brasília. Anais [...]. Brasília, DF: ANPAE, 2018a. Tema: Gestão pedagógica, organização curricular, qualidade da educação, direitos humanos, diversidade cultural e inclusão social.

BORGHI, R. Que educação é pública? A privatização de um direito. Revista ECCOS, n. 46, maio/jun. 2018b. Disponível em: https://periodicos.uninove.br/eccos/article/view/7832. Acesso em 8 dez. 2020.

BORGHI, R.; BERTAGNA, R. H. Que educação é pública? Análise preliminar do atendimento conveniado na educação infantil nas diferentes regiões administrativas brasileiras. Revista Brasileira de Estudos Pedagógicos, Brasília (DF), v. 97, p. 506-518, 2016. Disponível em: https://www.scielo.br/scielo.php?script=sci_arttext\&pid=S217666812016000300506. Acesso em: 12 out. 2020.

COSTOLA, A; BORGHI, R. Os reformadores empresariais e as políticas educacionais: análise do movimento todos pela base nacional comum. Revista on line de Política e Gestão Educacional, Araraquara, v. 22, n. esp. 3, p. 1313-1324, 2018. e-ISSN: 1519-9029. Disponível em: https://periodicos.fclar.unesp.br/rpge/article/view/11889. Acesso em: 12 maio 2020. 
FREITAS, L. A reforma empresarial da educação: nova direita, velhas ideias. São Paulo, SP: Expressão Popular, 2018.

FREITAS, L. Os reformadores empresariais da educação: da desmoralização do magistério à destruição do sistema público de educação. Educação e Sociedade, Campinas (SP), v. 33, n. 119, p. 379-404, abr./jun. 2012. Disponível em:

https://www.scielo.br/pdf/es/v33n119/a04v33n119.pdf. Acesso em 5 dez. 2020.

GARCIA, T. A organização do trabalho na escola e a participação dos educandos. Revista Educação teoria e prática, Brasília (DF), v. 14, n. 26, p. 67-93, 2006. Disponível em: https://www.periodicos.rc.biblioteca.unesp.br/index.php/educacao/article/view/410. Acesso em: 2 out. 2020.

GARCIA, T. et al. Sistemas privados de ensino em escolas municipais paulistas: implicações para o planejamento e o trabalho docente. In: SOUZA, D.; SARTI, F. (Org.). Mercado de formação docente: constituição, funcionamento e dispositivos. 1. ed. Belo Horizonte, MG: Fino Traço, 2014. v. 1, p. 263-284.

GIMENO SACRISTAN, J. O currículo: uma reflexão sobre a prática. Porto Alegre, RS: Artmed, 2000.

OLIVEIRA, R. O empresariado industrial e a educação brasileira. Revista Brasileira de Educação, Rio de Janeiro (RJ), n. 22, p. 47-60, 2003. Disponível em:

https://www.scielo.br/pdf/rbedu/n22/n22a06.pdf. Acesso em: 2 nov. 2020.

PARO, V. Educação para a democracia: o elemento que falta na discussão da qualidade do ensino. Revista Portuguesa de Educação, Braga (Portugal), v. 13. n. 1, p. 23-38, 2000. Disponível em: https://core.ac.uk/download/pdf/25652841.pdf. Acesso em: 5 nov. 2020.

PERONI, V. Múltiplas formas de materialização do privado na educação básica pública no Brasil: sujeitos e conteúdo da proposta. Currículo sem Fronteiras, v. 18, p. 1-27, 2018. Disponível em: http://www.curriculosemfronteiras.org/vol18iss1articles/peroni.pdf. Acesso 10 fev. 2020.

PONCE, B. O currículo e seus desafios na escola pública brasileira: em busca da justiça curricular. Currículo sem Fronteiras, v. 18, n. 3, p. 785-800, set./dez. 2018. Disponível em: http://www.curriculosemfronteiras.org/vol18iss3articles/ponce.pdf. Acesso em 18 out. 2019.

RAVITCH, D. Vida e morte do grande sistema escolar americano: como os testes padronizados e o modelo de mercado ameaçam a educação. Trad. Marcelo Duarte. Porto Alegre, RS: Sulina, 2011.

SADER, E. Público versus mercantil. Folha de S. Paulo, São Paulo, 19 jun. 2003. SANTOS, A. F. Pedagogia do mercado. Neoliberalismo, trabalho e educação no século XXI. Ibis Libris, 2012.

SILVA JÚNIOR, J. R.; SGUISSARDI, V. Novas faces da educação superior no Brasil. 2. ed. rev. São Paulo, SP: Cortez; Bragança Paulista, SP: USF-IFAN. 2001. 
SOUZA, D.; SARTI, F. Mercado simbólico de formação docente. In: SOUZA, D.; SARTI, F. (Org.). Mercado de formação docente: constituição, funcionamento e dispositivos. Belo Horizonte, MG: Fino Traço, 2013.

\section{Como referenciar este artigo}

BORGHI, F. R. Atuação do setor privado no processo de construção curricular: o sequestro dos fins públicos da educação. Revista on line de Política e Gestão Educacional, Araraquara, v. 25, n. 3, p. 2744-2758, set./dez. 2021. e-ISSN:1519-9029. DOI: https://doi.org/10.22633/rpge.v25i3.14903

Submetido em: $16 / 08 / 2021$

Aprovado em: 07/09/2021

Publicado em: 08/12/2021

RPGE- Revista on line de Política e Gestão Educacional, Araraquara, v. 25, n. 3, p. 2744-2758, set./dez. 2021. e-ISSN: 1519-9029 